\title{
PENERAPAN KESELAMATAN PADA PASIEN LUKA OLEH PERAWAT DI RS
}

\author{
ANGEL OKTAVIA PURBA / 181101099 \\ angeloktavia013@gmail.com
}

\begin{abstract}
ABSTRAK
Keselamatan pasien merupakan sistem yang bertujuan untuk memberikan asuhan terhadap pasien secara aman sebagai upaya mencegah kejadian yang tidak diinginkan (Kemenkes, 2011). Patient safety merupakan suatu upaya mencegah, menghindari dan memperbaiki hasil yang merugikan pasien atau cidera akibat dari proses memberikan pelayanan kesehatan (US National Safety Fuondation,1999). Tujuan dari penulisan ini adalah untuk mengetahui apa itu keselamatan pasien atau patient safety, mengetahui apa tujuan patien safety, dam untuk mengetahui bagaimana penerapan keselamatan pada pasien di Rumah Sakit. Metode penulisan ini adalah Literature Riview, dimana ini menganalisis artikel yang relevan dan berfokus pada tema Penerapan keselamatan pasien oleh perawat di Rumah sakit
\end{abstract}

\begin{abstract}
Patient safety is a system that aims to provide care to patients safely in an effort to prevent unwanted events (Ministry of Health, 2011). Patient safety is an effort to prevent, avoid and improve adverse outcomes of patients or injuries resulting from the process of providing health services (US National Safety Fuondation, 1999). The purpose of this paper is to find out what is patient safety or patient safety, knowing what is the purpose of patien safety, and to find out how the application of safety to patients in hospitals. This writing method is Riview Literature, where it analyzes relevant articles and focuses on the theme Application of patient safety by nurses in hospitals.
\end{abstract}

Kata Kunci : Patient Safety, Standart Keselamatan Pasien, Penerapan Keselamatan Pada Pasien.

\section{LATAR BELAKANG}

Dalam dunia medis atau kesehatan hampir semua tindakan mempunyai potensi resiko. Banyaknya tindakan yang akan diberikan, banyaknya jenis obat,banyaknya pasien di Rs dan staf Rumah sakityang cukup banyak menjadi potensi terjadinya kesalahan medis. Keselamatan pasien merupakan 
sistem yang bertujuan untuk memberikan asuhan terhadap pasien secara aman sebagai upaya mencegah kejadian yang tidak diinginkan (Kemenkes, 2011). Keamanan dan keselamatan pasien merupakan hal yang mendasar yang perlu diperhatikan oleh tenaga medis saat memberikan pelayanan. Keselamatan pasien adalah suatu sistem dimana Rumah sakit dan semua tenaga medis memberikan asuhan kepada pasien secara aman dan tidak terjadi cidera akibat kesalahan karena melakukan suatu tindakan ataupun sebaliknya. Setiap tindakan pelayanan kesehatan yang diberikan kepada pasien seharusnya memberi dampak positif agar tidak menimbulkan kerugian bagi klien. Banyaknya jenis obat, jenis pemeriksaan dan prosedur, serta jumlah pasien dan staf rumah sakit yang cukup besar, merupakan hal yang berpotensi terjadinya kesalahan dalam proses pemberian pelayanan kesehatan berupa kesalahan diagnosis, pengobatan, perawatan, serta kesalahan sistem lainnya sehingga berbagai kesalahan yang terjadi mengakibatkan insiden keselamatan pasien. Seluruh tindakan medis terhadap pasien pasti memiliki risiko tersendiri. Mempertimbangkan betapa pentingnya keselamatan, Rumah sakit dan para tenaga medis harus mampu memberikan pelayanan yang terbaik tanpa menyebabkan kesalahan yang dapat merugikan. Untuk itu dalam memperoleh keberhasilan dalam memberikan pelayanan .

\section{TUJUAN}

Tujuan dari penulisan ini adalah untuk mengetahui apa itu keselamatan pasien atau patient safety, mengetahui apa tujuan patien safety, dam untuk mengetahui bagaimana penerapan keselamatan pada pasien di Rumah Sakit.

\section{METODE}

Metode penulisan ini adalah Literature Riview, dimana ini menganalisis artikel yang relevan dan berfokus pada tema Penerapan keselamatan pasien oleh perawat di Rumah sakit. Adapun artikel yang digunakan dalam literature ini menggunakan sumber dari buku teks, jurnal dengan memasukan kata kunci. Penerapan keselamatan pasien oleh peawat di Rumah sakit .Adapun jurnal yang saya yang digunakan merupakan jurnal yang diterbitkan pada 10 tahun terakhir. 


\section{HASIL}

Berdasarkan pencarian literature didapatkan pengertian patien safety atau keselamatan pasien, apa saja tujuan sistem patient safety. Mengetahui bagaimana penerapan keselamatan pasien oleh perawat di Rumah Sakit.

\section{PEMBAHASAN}

Keselamatan pasien merupakan sistem yang bertujuan untuk memberikan asuhan terhadap pasien secara aman sebagai upaya mencegah kejadian yang tidak diinginkan (Kemenkes, 2011). Keselamatan pasien adalah suatu sistem yang membuat asuhan pasien lebih aman, meliputi asesmen risiko, identifikasi dan pengelolaan risiko pasien, pelaporan dan analisis insiden, kemampuan belajar dari insiden dan tindak lanjutnya, serta implementasi membuat solusi untuk meminimalkan timbulnya risiko dan mencegah terjadinya cedera yang disebabkan oleh kesalahan akibat melaksanakan suatu tindakan atau tidak mengambil tindakan yang seharusnya diambil dalam pelayanan kesehatan Rumah sakit dalam melaksanakan tujuan, fungsi dan perannya memerlukan suatu bentuk pengaturannya yang jelas. Banyak unsur-unsur yang terkandung di dalam penyelenggaraan Rumah Sakit terutama terkait dengan tugas utamanya dalam pelayanan publik yakni melakukan pelayanan kesehatan, maka membutuhkan perangkat hukum yang memadai. Hal itu dimaksudkan agar penyelenggaraannya sungguh-sungguh dapat sesuai dengan kedudukan, peran dan fungsinya, serta terutama untuk dapat memenuhi amanat konstitusi yaitu mewujudkan kesejahteraan masyarakat. Keselamatan didefinisikan sebagai kebebasan dari cedera psikologis dan fisik. Menurut World Health Organization (WHO), keselamatan pasien adalah tidak adanya bahaya yang mengancam kepada pasien selama proses pelayanan kesehatan. Berdasarkan Peraturan Menteri Kesehatan Nomor 11 Tahun 2017, keselamatan pasien merupakan suatu sistem yang membuat asuhan pasien lebih aman, meliputi asesmen risiko, identifikasi dan pengelolaan risiko pasien, pelaporan dan analisis insiden, kemampuan belajar dari insiden dan tindak lanjutnya, serta implementasi solusi untuk meminimalkan timbulnya risiko dan mencegah terjadinya cedera yang disebabkan oleh kesalahan akibat melaksanakan suatu tindakan atau tidak mengambil tindakan yang seharusnya 
diambil. Menurut National Health Performance Committee (NHPC, 2001,dikutip dari Australian Institute Health and Welfare (AIHW, 2009) mendefinisikan keselamatan pasien adalah menghindari atau mengurangi hingga ketingkat yang dapat diterima dari bahaya aktual atau risiko dari pelayanan kesehatan atau lingkungan dimana pelayanan kesehatan diberikan. Keselamatan pasien adalah sebagai upaya untuk melindungi pasien dari sesuatu yang tidak diinginkan selama proses perawatan. Ini merupakan salah satu kebutuhan dasar yang harus dipenuhi pelayanan kesehatan dengan cara yang aman dan dalam lingkungan masyarakat yang aman merupakan hal penting untuk kesejahteraan dan ketahanan hidup pasien. Perawat menerapkan keterampilan berpikir kritis dan bertanggung jawab mengkaji adanya bahaya yang mengancam klien dan lingkungan. Dengan begitu, perawat menjadi penyedia pelayanan akut, restoratif, dan berkesinambungan yang aman dan juga menjadi partisipan aktif dalam promosi kesehatan. Penerapan keselamatan pada pasien dengan Pelaksanaan tujuh langkah menuju keselamatan pasien dapat memastikan pelayanan yang diberikan menjadi lebih aman, dan jika terjadi sesuatu hal yang tidak benar bisa segera diambil tindakan yang tepat. Tujuh langkah menuju keselamatan pasien terdiri dari: 1. Membangun kesadaran akan nilai Keselamatan Pasien. Ciptakan kepemimpinan dan budaya yang terbuka dan adil 2. Memimpin dan mendukung staf. Membangun komitmen, fokus dan jelas tentang keselamatan pasien 3. Mengintegrasikan aktivitas pengelolaan risiko. Kembangkan sistem dan proses pengelolaan risiko serta lakukan identifikasi dan kajian hal yang potensial bermasalah. 4 . Mengembangkan sistem pelaporan. Pastikan staf agar dengan mudah dapat melaporkan kejadian/insiden, serta rumah sakit mengatur pelaporan kepada KKPRSsekarang berubah menjadi KNKP. 5. Melibatkan dan berkomunikasi dengan pasien. Kembangkan cara-cara komunikasi yang terbuka dengan pasien 6. Belajar dan berbagi pengalaman tentang keselamatan pasien. Dorong staf untuk melakukan analisis akar masalah untuk belajar bagaimana dan mengapa kejadian terjadi 7. Mencegah cedera melalui implementasi sistem Keselamatan Pasien. Gunakan 
informasi yang ada tentang kejadian/maslah untuk melakukan perubahan sistem. Selain ketujuh langkah menuju keselamatan terdapat juga 7 standart keselamatan pasien wajib diterapkan fasilitas pelayanan kesehatan. Standar keselamatan pasien meliputi tujuh standar yaitu 1. Hak pasien, pasien dan keluarga mempunyai hak untuk mendapat informasi tentang rencana dan hasil pelayanan. 2 . Pendidikan bagi pasien dan keluarga, rumah sakit harus mendidik pasien dan keluarganya tentang kewajiban dan tanggung jawab pasien dalam asuhan pasien. 3. Keselamatan pasien dalam kesinambambungan pelayanan, rumah sakit menjamin kesinambungan pelayanan dan menjamin koordinasi antar tenaga dan antar unit pelayanan. 4 . Penggunaan metode peningkatan kinerja untuk melakukan evaluasi dan peningkatan keselamatan pasien, rumah sakit harus mendisain proses baru atau memperbaiki proses yang ada, memonitor dan mengevaluasi kinerja melalui pengumpulan data, menganalsis secara intensif KTD, dan melakukan perubahan untuk meningkatkan kinerja serta keselamatan pasien. 5. Peran kepemimpinan dalam meningkatkan keselamatan pasien 6. Pendidikan bagi staf tentang keselamatan pasien 7 . Komunikasi sangat penting bagi tenaga kesehatan untuk mencapai keselamatan pasien.

\section{KESIMPULAN}

Keselamatan pasien adalah menghindari atau mengurangi hingga ketingkat yang dapat diterima dari bahaya aktual atau risiko dari pelayanan kesehatan atau lingkungan dimana pelayanan kesehatan diberikan. keselamatan pasien sudah menjadi tuntutan masyarakat maka pelaksanaan program keselamatan pasien rumah sakit perlu dilakukan. Berkaitan dengan tuntutan keselamatan pasien tersebut maka diperlukan acuan yang jelas untuk melaksanakan keselamatan pasien tersebut. Dalam penerapan keselamatan pasien di rs sudah terdapat 7 langkah menuju keselamatan dan juga terdapat 7 standart keselamatan pasien wajib diterapkan fasilitas pelayanan kesehatan dan semua pemberi layanan kesehatan termasuk perawat.

\section{SARAN}

Dalam penerapan keselamatan pada pasien harus sepenuhnya dilaksanakan dengan baik dan benar dan mengukuti aturan yang berlaku untuk 
meningkatkan nilai keselamatan yang lebih baik serta pengetetahuan perawat juga sangat penting dalam pelaksanaan sasaran keselamatan pasien.

\section{DAFTAR PUSTAKA}

Arruum,D.,Salbiah.,Manik,M.

(2015).Pengetahuan Tenaga Kesehatan

Dalam Sasaran Keselamatan Pasien Di

Rumah Sakit Universitas Sumatera

Utara: Idea Nursing Journal.6,(2):1-4.

Azrul, A. (1996). Мепији

PelayananKesehatan Yang Bermutu .

Jakarta : Salemba Medika.

Dapartemen Kesehatan RI. (2008)

Upaya Peningkatan Mutu

Pelayanan Rumah sakit. Jakarta

Depkes RI.

Firawati. (2012). Pelaksanaan Program Keselamatan Pasien di RSUD Solok. Jurnal Kesehatan Masyarakat, Vol 6, No 2.

Gede, Muninjaya A.A. (2011).

Manajemen Mutu Pelayanan Kesehtan.

Jakarta : EGC.

Hakim, Lukman.,Widodo,J. (2014).

Optimalisasi Proses Koordinasi

Program Keselamatan Pasien
(Patient Safety) Di Rumah Sakit.

Jurnal Administrasi Kesehatan

Indonesia. 198-208.

Harus, B. D.(2015). Pengetahuan

Perawat Tentang Keselamatan Pasien

dengan Pelaksanaan Prosedur

Keselamatan Pasien Rumah Sakit

(KPRS) di Rumah Sakit Panti Waluyu

Sawahan Malang. Jurnal CARE, Vol 3, No1.

Ismainar, Hetty. (2015). Keselamatan

Pasien di Rumah Sakit. Yogyakarta :

Deepublish.

Permenkes RI. (20170. Peraturan

Menteri Kesehatan Republik Indonesia

Nomor 11 Tahun 2017 Tentang

Keselamatan Pasien. Jakarta : Depkes

RI.

Potter \& Perry.(2005). Fundamental

Keperawatan : Konsep Proses dan

Praktek. Jakarta : Salemba Medika.

R.H Simamora. (2019). Buku Ajar

Pelaksanaan Identifikasi Pasien :

Uwais Inspirasi Indonesia.

R.H. Simamora. (2019). Documentation Of Patient Identification Into The Electronic System to Improve the 
Quality of Nursing Service.

Internasional Journal Of Sciiebtific \&

Technology Research, Vol 08(09),18841886.

R.H. Simamora. (2019). The Influence Of Training Handover Based SBAR

Communication For Improving Patients

Safety. Indian Journal Of Public Health Research \& Development, Vol 09, 1280-1285.

Rivai, Fridawaty, dkk.(2016). Faktor

Yamh Berhubungan Dengan

Keselamatan Pasien di RSUD

Ajjppannge Sopeng Tahun 2015. Jurnal

Kebijakan Kesehatan Indonesia, vol.5,

No.4.

Roper, Nancy. (1996). Prinsip-Prinsip

Keperawatan. Yogyakarta : Andi

Yayasan Essentia Medica

Sumarni. (2017). Analisis Implementasi

Patient Safety Terkait Peningkatan

Mutu Pelayanan Kesehaatan di RS.

Jurnal Ners dan Kebidanan Indonesia.

91-99.

Ulumiyah, N. H. (2018). Meningkatkan

Mutu Pelayanan Kesehatan dengan

Penerapan Upaya Keselamatan Pasien di Puskesmas. Jurnal Administrasi

Kesehatan Indonesia, Vol 6(2) : 149-

155

Utarini, A, Djasri, H. (2012).

Keselamatan pasien dan Mutu

Pelayanan kesehatan. Jurnal

Manajemen Pelayanan Kesehatan. 159160. 
